\title{
Bioinspired Synthesis of Gold Nanoparticles Using Ficus Benghalensis (Indian Banyan) Leaf Extract
}

\author{
G. FRANCIS, R. THOMBRE* , F. PAREKH and P. LEKSMINARAYAN
}

Life Sciences Research Centre, Department of Biotechnology, Modern College of Arts, Science and Commerce, Shivajinagar, Pune-411005, India rebecca.thombre@gmail.com

Received 3 July 2013 / Accepted 18 August 2013

\begin{abstract}
Gold nanoparticles have immense applications due to its unique properties. A simple and facile method for synthesis of gold nanoparticles was developed using leaf extracts of Ficus benghalensis (Indian Banyan). The phytoconstituents and reducing compounds present in the leaf extract reduces aqueous gold chloride rapidly to nanogold $\left(\mathrm{Au}^{\circ}\right)$. The gold nanoparticles are biostabilized due to the plant constituents and their production is confirmed due to surface plasmon resonance (SPR) as evidenced by UV-Vis spectrophotometry. FTIR analysis confirms the presence of amino groups present due to the capping of nanoparticles by plant peptides. The even and circular size was observed by TEM. The crystalline nature was confirmed using selective area electron diffraction crystallographic experimental technique. The gold nanoparticles demonstrated potent antimicrobial activity against selected gram positive and negative bacteria.
\end{abstract}

Keywords: Gold nanoparticles, Ficus benghalensis, Phytoconstituents, Antimicrobial

\section{Introduction}

Nanotechnology is emerging field of science which involves synthesis and applications of nano particles. Elemental gold and gold nanoparticles have many applications due to their novel properties and applications in biomedical field. As there is an increase in microbial organisms that are resistant to multiple antibiotics the focus of researchers is the development of new and effective antimicrobial reagents that are cost effective and highly efficient. One of the important bactericidal properties of nanoparticles is that, it can penetrate into the cell and causes damage, as it interacts with phosphorous and sulfur containing compounds such as DNA and protein ${ }^{1}$. As a result of this, gold nanoparticles are considered as potent anticancer, antimicrobial and cytotoxic agents.

Gold nanoparticles can be synthesized by physical, chemical and biological method. Biological method of nanoparticles synthesis involves the application of extracts or enzymes derived from plant, fungi or bacteria. This bioinspired method of synthesis is safe, economical and eco-friendly. Gold nanoparticles synthesis has been previously reported using extracts of onion, lemon grass, tea and cinnamon ${ }^{2-5}$. 
Ficus benghalensis (Indian Banyan tree) has a great medicinal value and has abundant phytoconstituents including ketones, flavonols, flavonoids, terpenoids, sterols, oentacyclic triterpenes and triterpenoids, furocoumarin, tiglic acid ester coumarins, esters, carbohydrates and serine proteases. Banyan leaf extracts have antidiabetic, hypolipidemic, anthelmintic, antibacterial, immunomodulatory and antioxidant properties ${ }^{6}$. In the present study, we report the green synthesis of biologically stabilized gold nanoparticles using leaf extract of Ficus benghalensis (Banyan) as reducing as well as capping agent. The gold nanoparticles can be applied effectively to control microorganisms and preventing infections caused due to them.

\section{Experimental}

The leaves of Ficus benghalensis were collected and thoroughly washed twice with sterile distilled water. $10 \mathrm{~g}$ of leaves were crushed and added in $100 \mathrm{~mL}$ of sterile distilled water. The extract was filtered using Whatman no. 41 filter paper and was used immediately for synthesis of gold nanoparticles.

\section{Synthesis of gold nanoparticles}

Gold nanoparticles were synthesized by addition varying volumes of Ficus benghalensis leaf extract to ten $\mathrm{mL}$ of $10 \mathrm{mM}$ Auric chloride $\left(\mathrm{HAuCl}_{4}\right)$ to obtain a concentration of 1 :1, 1:2, 1:4, 1:8 (plant extract: gold chloride).The reaction mixture was incubated for 5-7 min at $30{ }^{\circ} \mathrm{C}$. Synthesis of nanoparticles is confirmed by the change of color of gold chloride to pink $^{3}$.

\section{Characterization of nanoparticles}

The reduction of pure $\mathrm{Au}^{+}$ions was studied by observation of surface plasmon resonance using a double beam spectrophotometer (Shimadzu, UV-2450). The morphology of the obtained nanoparticles was characterized by using analytical Transmission electron microscope. FTIR spectra was measured on Jasco FT/IR- 16100. The XRD analysis was performed on Bruker axs D8ADVANCE.

\section{Results and Discussion}

\section{Synthesis of gold nanoparticles}

The synthesis of gold nanoparticles was performed using Ficusbenghalensis (Banyan) leaf extract as a reducing agent. The reduction of gold chloride to nano gold resulted in colour change (Figure 1).
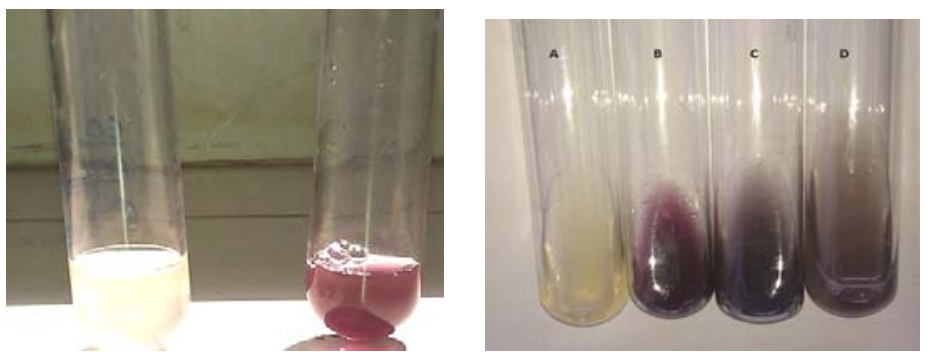

Figure 1. (a) Photograph of gold chloride solution before (yellow) and after (purple) addition of Banyan leaf extract. (b) Colour change observed after addition of various volumes of leaf extract to gold chloride: $A$ - Gold chloride, $B$ - Gold choride and leaf extract $(1: 1 \mathrm{v} / \mathrm{v})$, $C$-Gold choride and leaf extract (1:2v/v) and $D$-Gold choride and leaf extract (1:4v/v) 
The Ficus benghalensis leaf extract shows colour change from pale yellow to purple colour within $5 \mathrm{~min}$ after addition of $\mathrm{HAuCl}_{4}$ solution. The typical purple color was observed when equal volume of leaf extract was added to gold chloride solution. This optimum concentration of leaf extract was used for further studies.

\section{Characterization of gold nanoparticles}

The gold nanoparticles were characterized by observation of surface plasmon resonance maxima of the leaf extract of banyan and gold nanoparticles.

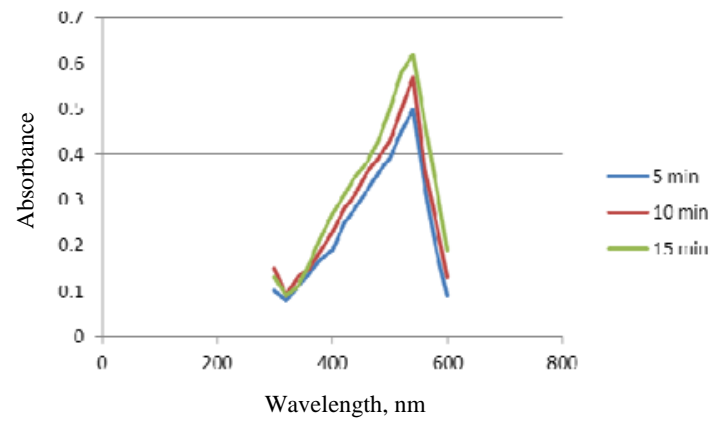

Figure 2. UV-Vis absorption spectrum of biostabilized gold nanoparticles synthesized using leaf extract of Banyan

This peak is attributed to nanoparticles with sizes ranging from $2 \mathrm{~nm}$ to $100 \mathrm{~nm}^{7}$ (Figure 2). Absorption maxima was observed at $530 \mathrm{~nm}$ which is characteristic of gold nanoparticles. The gold nanoparticles were further characterized using TEM, XRD and FTIR analysis.

\section{TEM analysis}

The size and morphology of gold nanoparticles was studies using TEM. The gold nanoparticles and were even in size and were spherical in shape. The Selected Area Electron Diffraction (SAED) pattern proved that the nanoparticles were crystalline in nature. The transmission electron micrograph and SAED pattern is represented in Figure 3.
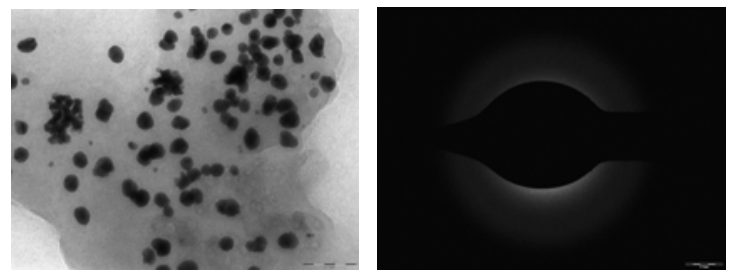

Figure 3. Transmission electron micrograph and SAED pattern of biostabilized gold nanoparticles

\section{FTIR analysis}

FTIR analysis reveals a set of unique peaks that prove the presence in the sample. The FTIR spectra of biostabilized gold nanoparticles is presented in Figure 4. The FTIR analysis of biostabilized gold nanoparticles confirmed the presence of proteins, peptides and carbohydrates. Typical peaks at 3500, 2900, 1885, 1300, 1150, $600 \mathrm{~cm}^{-1}$ were observed. The band at 1150 and $600 \mathrm{~cm}^{-1}$ are attributed to $\mathrm{C}-\mathrm{H}$ and C-C stretching vibration for aromatic rings, the band at 3500 are suggestive of $\mathrm{O}-\mathrm{H}$ stretch due to carbohydrates, alcohols or phytoconstituents, whereas band at 1300 and $2900 \mathrm{~cm}^{-1}$ was assigned to aliphatic amines and 
C-N vibrations acquired due to presence of proteins respectively ${ }^{8}$. The FTIR analysis indicates the presence of proteins, phytoconstituents and carbohydrates which stabilize and cap the gold nanoparticles.

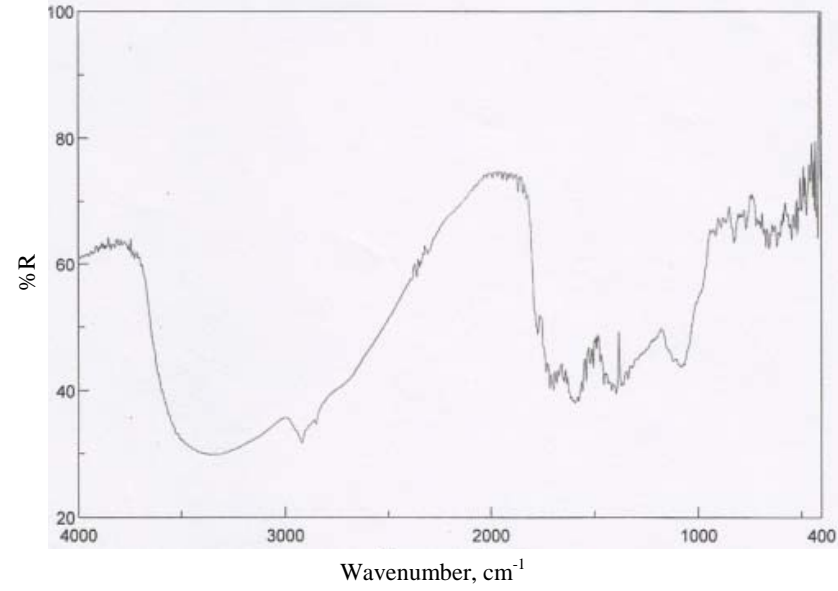

Figure 4. FTIR spectra of nanoparticles

The antibacterial activity of gold nanoparticles was studied against Escherichia coli, Bacillus subtilis, Staphlococcus aureus and Klebsiella pneumonia. The gold nanoparticles demonstrated a zone of inhibition against all the test organisms with maximum inhibition against gram positive organism (Figure 5).

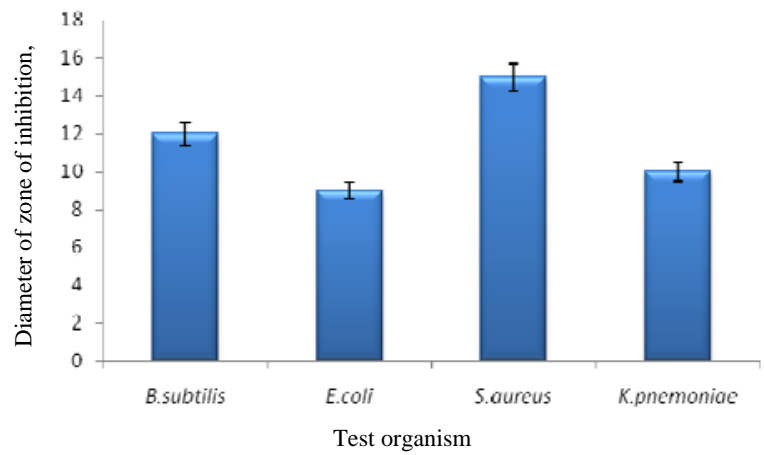

Figure 5. Antibacterial activity

\section{Conclusion}

The biostabilized gold nanoparticles were synthesized using leaf extract of Ficus benghalensis (Indian Banyan). The gold nanoparticles were spherical, stable and were characterized using UV-Vis spectrophotometry, TEM, SAED and FTIR analysis. The gold nanoparticles demonstrated potent antimicrobial activity against selected gram positive and negative bacteria. Thus a rapid, eco-friendly and economical method for synthesis of biostabilized gold nanoparticles was developed.

\section{Acknowledgement}

We are grateful to SAIF, IIT-Bombay for TEM analysis. We are grateful to University Grants Commission (UGC), Delhi for financial support. 


\section{References}

1. Thombre R, Mehta S, Mohite J and Jaisinghani P, Int J Pharm Bio Sci., 2013, 4(1), 184-192.

2. $\quad$ Parida U K, Bindhani B K and Nayak P, World J Nano Sci Eng., 2011, 1, 93-98.

3. Shiv S S, Rai A, Ankamwar B, Singh A, Ahmad A and Sastry M, Nature Mater., 2004, 3(7), 482-488; DOI:10.1038/nmat1152

4. Nune S, Chanda N, Shukla R, Katti K, Kulkarni R, Thilakavathy S, Mekapothula S, Kannan R and Katti K, J Mater Chem., 2009, 10, 2912-2920; DOI:10.1039/B822015H

5. Huang J, Li Q, Sun D, Lu Y, Su Y, Yang X, Wang H, Wang Y, Shao W, Hong N J and Chen C, Nanotechnology, 2007, 18(10), 105104-105115; DOI:10.1088/0957-4484/18/10/105104

6. Rao H, Akhtar M, Ahmad I, Muhammad M, Hayat I, Iqbal Z and Rahman N, J Med Plants Res, 2011, 5, 6393-6400.

7. Henglein A, J Phys Chem B, 1993, 97(21), 5457-5471; DOI:10.1021/j100123a004

8. Lokina S and Narayanan V, Chem Sci Trans., 2013, 2(S1), S105-S110; DOI:10.7598/cst2013.22 